\section{Life-long learning to improve your skills}

Changes in patient demographics and an increase in expectations has meant that modern dental practice has become increasingly complex and challenging, according to the Peninsula Dental School at the University of Plymouth.

Modern clinical practice requires dentists to provide wellplanned and executed care for patients who are better informed about their care than ever before. Consequently there is a need to provide predictable and technically excellent care, based on up-to-date literature.

The postgraduate taught courses run by Peninsula Dental School teach students advanced clinical skills which can be applied immediately in their own practices.

The three-year MSc courses in Oral Surgery, Periodontology and Restorative dentistry combine lectures with technique courses in the simulation suite for 20 days each year for the first two years. Students can then apply these skills to their own patients, and develop more advanced skills as they progress on the course.

The third and final year is the dissertation, in which students are supported to use the skills that they have acquired to ask and answer questions relevant to clinical scenarios in their own practice. This equips them to keep up to date with developments in dentistry for the rest of their career.

Further information is available at https://www.plymouth. ac.uk/your-university/about-us/university-structure/faculties/ medicine-dentistry/postgraduate-education-for-medicine-anddentistry or by emailing meddent-admissions@plymouth.ac.uk.

\section{Combining aesthetics and functionality}

Achieve the perfect aesthetic with Filtek One bulk fill restorative from $3 \mathrm{M}$ Oral Care.

With one-step fast placement, and 3M nanotechnology, increased opacity offers improved aesthetics compared to the previous Filtek Posterior bulk fill restorative, without compromising depth of cure.

Available in five shades, Filtek One restorative is designed for the posterior and will adapt to the cavity easily. Patients will experience the benefits of excellent polish retention with a result that is functional, as well as beautiful, thanks to high wear resistance.

Make Filtek One bulk fill restorative your first choice for aesthetic outcomes in a value product, as there's no need for expensive dispensing devices.

For more information, call 0800626578

or visit www.3m.co.uk/Dental.

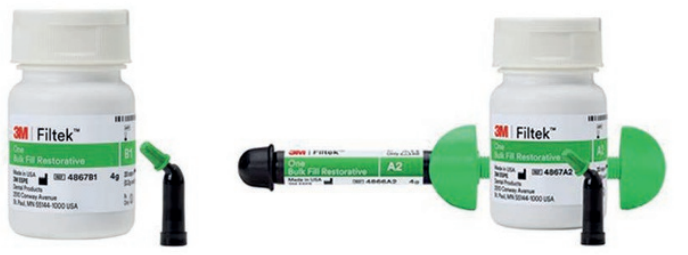

\section{The key to a pearly white smile}

Having white teeth can improve a patient's confidence and selfesteem, so give them the key to a brighter smile with premium Saber Tooth White Home Kits from CosTech Dental Laboratory.

Benefitting from being custom-fit, the bleach trays are ultra-thin and virtually invisible meaning wearers can continue their daily activities without having to worry. Furthermore, the seamless fit of the trays hugs the contours of every tooth accurately, guaranteeing that patients will achieve the best possible coverage.

Due to the trays' custom-fit, the bleaching gel is exposed to teeth without potential leakage onto the gums. This prevents any discomfort or irritation and means that patients can use the gel safely to ensure they always end up with a brilliant shine.

Give your patients the chance to improve their confidence today by contacting CosTech Dental Laboratory for more information.

For more information, please visit www.sabertoothwhite.com

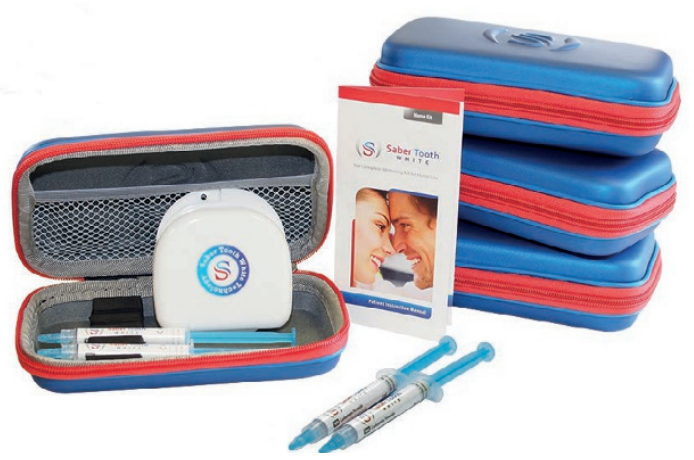

\section{Expert help in root canal treatment}

The CanalPro Apex Locator from COLTENE can be used either alongside radiographs or as an alternative to accurately confirm the working length of any root canal.

The device's simple, userfriendly and intuitive design means that it is ideal for both skilled endodontic experts and general dental practitioners with less experience in performing root canal treatments.

Using electrical resistance, the Apex Locator not only displays a virtual apex function on the LCD colour screen for visual confirmation, but also provides audio feedback for the dentist.

Best of all, accurate results can be achieved in canals regardless of whether they are in wet or dry condition, guaranteeing verification with every use.

To find out more about the CanalPro Apex Locator, or the handy, space-saving CanalPro Apex Locator Compact version, contact COLTENE.

To find out more, visit www.coltene.com, email info.uk@ coltene.com or call 01444235486. 